\title{
Editorial
}

Pascale Ehrenfreund

\section{Introduction to the Special Issue "The Global Space Exploration Conference (GLEX) 2021"}

https://doi.org/10.1515/astro-2021-0005

Dear Readers,

We take great pleasure in welcoming you to our Special Issue dedicated to the Global Space Exploration Conference (GLEX 2021) ${ }^{1}$. We have created this publication with the intention of providing a space for the generation of knowledge, dialogue, critique, debate, and collaboration among the global space exploration community.

The Global Space Exploration Conference (GLEX 2021) organized by the International Astronautical Federation (IAF) and hosted by ROSCOSMOS was held in St. Petersburg from 14 to 18 June and will be certainly remembered as the first in-person event dedicated to Space during the Covid-19 era.

The event was an exceptional occasion to celebrate the $60^{\text {th }}$ anniversary of Yuri Gagarin's spaceflight and the resilience of the global space community. The tremendous success of the conference which attracted over 800 attendees from 34 countries and 1500 people connected from remote confirmed the strong importance of converging into one same place to discuss in-depth the various issues of space exploration.

The preparation of this special issue has been an interesting journey in many aspects. Our vision was to create a high-quality publication that is relevant, challenging, thought-provoking, and inclusive of a diverse range of voices and perspectives, including, academic researchers and scholars, entrepreneurs, policymakers, and students.

The Technical Programme welcomed 580 abstract submissions out of which 410 were accepted. Together, the final twelve papers selected for the GLEX 2021 Best Technical Presentations Award and included in this special issue reflect the rich variety of inspiring topics from international cooperation, Mars and lunar exploration to key technologies and space transportation as well as depth of theoretical, methodological, and practical approaches and challenges relevant to space exploration.

We take this opportunity to thank our authors, co-authors, the International Programme Committee, the reviewers and co-editors, and all of whom have volunteered to contribute to the publication of the GLEX 2021 Special Issue. We are delighted that you are joining us as readers and hope you will also join us as contributors in the future.

Prof. Pascale Ehrenfreund

\footnotetext{
Pascale Ehrenfreund: President, International Astronautical Federation (IAF); President, International Space University (ISU); Research Professor, Space Policy \& International Affairs at Space Policy Institute, George Washington University, The United States of America

1 www.iafastro.org

๖ Open Access. ( 2021 P. Ehrenfreund, published by De Gruyter 